ASTHMA

\title{
Failure of sputum eosinophilia after eotaxin inhalation in asthma
}

\author{
D Bumbacea, J Scheerens, B S Mann, R G Stirling, K F Chung
}

Thorax 2004;59:372-375. doi: 10.1136/thx.2003.010199

\begin{abstract}
See end of article for authors' affiliations

.....................

Correspondence to: Professor K F Chung, National Heart and Lung Institute, Imperial College, Dovehouse Street, London SW3 6LY, UK; f.chung@ imperial.ac.uk
\end{abstract}

Received 12 May 2003 Accepted 10 December 2003

\begin{abstract}
Background: Eotaxin is a chemokine specific for eosinophils and may play an important role in eosinophil recruitment in asthma. The effects of eotaxin inhalation on sputum and blood eosinophils, exhaled nitric oxide (NO), and bronchial responsiveness were determined.

Methods: Eotaxin was administered by nebulisation to asthma patients in three studies: (1) an open dose finding study with eotaxin $(5,10$ and $20 \mu \mathrm{g}$ ) to two asthmatic subjects; (2) a randomised placebo controlled study with $20 \mu \mathrm{g}$ eotaxin to five asthmatic subjects and five normal volunteers; and (3) a randomised placebo controlled study with $40 \mu \mathrm{g}$ eotaxin to nine asthmatics. Forced expiratory volume in 1 second $\left(\mathrm{FEV}_{1}\right)$, exhaled $\mathrm{NO}$, and blood eosinophils were measured before and hourly for 5 hours after nebulisation and at 24 and 72 hours. Methacholine bronchial challenge and sputum induction were performed before and at 5, 24, and 72 hours after nebulisation.

Results: In the two placebo controlled studies there was no change in sputum eosinophil count and sputum eosinophilic cationic protein concentration after eotaxin inhalation compared with placebo. $\mathrm{FEV}_{1}$, exhaled $\mathrm{NO}$, and methacholine $\mathrm{PC}_{20}$ did not change. However, high dose eotaxin $(40 \mu \mathrm{g})$ induced an increase in sputum neutrophil count compared with placebo $(p<0.05)$.

Conclusions: Inhaled eotaxin up to $40 \mu \mathrm{g}$ induced no changes in sputum eosinophil count but at $40 \mu \mathrm{g}$ it increased the sputum neutrophil count. The significance of this finding is unknown.
\end{abstract}

$\mathrm{E}$ otaxin is a CC chemokine which was first isolated from guinea pig bronchoalveolar lavage (BAL) fluid. ${ }^{1}$ It selectively binds to a specific receptor (CCR3) which has been cloned ${ }^{2}{ }^{3}$ and which is selectively and highly expressed on eosinophils, ${ }^{2}$ basophils, mast cells, and T helper type 2 cells ${ }^{4}$ - cells which may be important in the pathogenesis of asthma. Inhalation or skin injection of eotaxin in guinea pigs is associated with an on-site increase in eosinophils. ${ }^{5}$ Eotaxin and CCR3 mRNA are highly expressed in the bronchial tissue of asthmatic patients, both atopic and non-atopic. ${ }^{6}$ It has also been found in high concentrations in BAL fluid ${ }^{7}$ and eotaxin mRNA is highly expressed in sputum cells $^{8}$ from asthmatic patients. The extent of eotaxin mRNA expression in the bronchial mucosa of asthmatic patients has been positively correlated with airway eosinophil count, bronchial hyperresponsiveness, and symptom scores. ${ }^{9}$ These findings strongly indicate a role for eotaxin in the eosinophilic airway inflammation characteristic of asthma.

To determine the potential role of eotaxin in asthma, we determined whether eotaxin administered by inhalation could induce pulmonary eosinophilia. Exhaled nitric oxide (NO), cells in induced sputum, lung function, bronchial responsiveness, and circulating eosinophil counts were measured.

\section{METHODS}

Three consecutive studies were performed. The first was an open label dose finding and safety study in which increasing concentrations of eotaxin $(5,10$, and $20 \mu \mathrm{g})$ were each administered to two patients with asthma (total of six subjects). The second study was a double blind, placebo controlled, crossover, randomised study in which $20 \mu \mathrm{g}$ eotaxin was administered to five asthmatic subjects and five normal volunteers (low dose study), while the third study was a double blind, placebo controlled, crossover, randomised study of $40 \mu \mathrm{g}$ eotaxin in nine asthmatic subjects (high dose study).
Baseline measurements of forced expiratory volume in 1 second $\left(\mathrm{FEV}_{1}\right)$, exhaled $\mathrm{NO}$, and blood eosinophil count were performed immediately before eotaxin or placebo inhalation and 3-5 days before induced sputum and methacholine bronchial challenge. After eotaxin/placebo inhalation, $\mathrm{FEV}_{1}$, exhaled NO, and blood eosinophil count were measured at $0.5,1,2,3,4,5,24$, and 72 hours and methacholine bronchial challenge followed by sputum induction were performed at 5, 24, and 72 hours. In placebo controlled studies eotaxin and placebo administration were in randomised order and were separated by a 2 week interval.

\section{Subjects}

Asthma patients were recruited according to a diagnosis of mild persistent asthma as defined by current GINA guidelines. ${ }^{10}$ They were lifelong non-smokers with a provocative concentration of methacholine that caused a $20 \%$ decrease in $\mathrm{FEV}_{1}$ (methacholine $\mathrm{PC}_{20}$ ) of $<8 \mathrm{mg} / \mathrm{ml}$ and an $\mathrm{FEV}_{1}$ of $>65 \%$ predicted and no history of other respiratory disease. Subjects recruited to the study should have had no asthma exacerbation and/or respiratory infection in the previous 4 weeks, no use of corticosteroid treatment (inhaled and/or systemic) in the previous 3 months, and use of only rescue inhaled rapid acting $\beta_{2}$ agonist (less than once a day). Normal volunteers had no history of respiratory disease, no evidence of atopy (negative history and skin prick tests), and a methacholine $\mathrm{PC}_{20}$ of $>16 \mathrm{mg} / \mathrm{ml}$. The Royal Brompton \& Harefield Hospital ethics committee approved the protocols and each subject signed an informed consent.

\section{Study design}

Human recombinant eotaxin (carrier free with $<1.0 \mathrm{EU}$ endotoxin/l $\mu$ g eotaxin; R\&D Systems, Abingdon, UK) or placebo was administered by inhalation using a jet nebuliser (MEDIC-AID, Pagham, UK) in $2 \mathrm{ml}$ normal saline with $0.1 \%$ human serum albumin. After the first $2 \mathrm{ml}$ was nebulised, a 
further $2 \mathrm{ml}$ normal saline was added and nebulised to ensure complete administration of eotaxin.

$\mathrm{FEV}_{\mathrm{I}}$ was measured using a spirometer (Vitalograph, Buckingham, UK). The best of three reproducible attempts was recorded. Predicted values were those published by the European Respiratory Society (ERS). Methacholine bronchial challenge was performed according to current ERS guidelines. Increasing concentrations of methacholine were given by inhalation via a dosimeter (Mefar, Bovezzo, Italy) and $\mathrm{FEV}_{1}$ was measured after each inhalation. The $\mathrm{PC}_{20}$ was calculated by interpolation on the logarithmic dose-response curve. Exhaled NO was measured with a chemiluminescence analyser (model LR2000, Logan Research, Rochester, UK) using a previously described method. ${ }^{11}$ The mean values were taken from the point corresponding to the end of the plateau of exhaled carbon dioxide, representing the lower respiratory tract sample. The mean of two consecutive measurements was recorded. Eosinophil blood count was performed using an automated haematology analyser (Advia, UK).

Sputum induction and processing were performed according to a previously published method. ${ }^{12}$ After methacholine challenge, subjects inhaled $200 \mu \mathrm{g}$ salbutamol and $\mathrm{FEV}_{1}$ and peak expiratory flow (PEF) were measured 30 minutes later. Subjects then inhaled hypertonic saline $(3.5 \%)$ from an ultrasonic nebuliser (Ultraneb 2000, deVilbiss, Somerset, PA, USA) for three consecutive periods of 5 minutes each. Sputum induction was stopped if $\mathrm{FEV}_{1}$ fell to $<80 \%$ of baseline. Sputum processing was performed in the first 2 hours after induction. Sputum was mixed with $0.1 \%$ DTT (dithiothreitol, Sigma-Aldrich, Poole, UK) filtered through a $70 \mu \mathrm{m}$ cell strainer and centrifuged at $300 \mathrm{~g}$ for 10 minutes at $4^{\circ} \mathrm{C}$. The supernatant was stored at $-70^{\circ} \mathrm{C}$ for later assays. The cell pellet was resuspended in Hank's balanced salt solution (Sigma-Aldrich) up to $1 \mathrm{ml}$ and total cell count, total inflammatory cell count, and viability were assessed. Samples were discarded if they had $>80 \%$ squamous cell contamination or $<80 \%$ viability. Slides were prepared by cytocentrifugation (Cytospin 3, Shandon Scientific, Runcorn, Cheshire, UK) using 25000 inflammatory cells per slide and stained with Diff-Quick (Merz \& Dale, Dudingen, Switzerland). Differential cell counts were made on two different slides for each sample, counting at least 300 inflammatory cells per slide, and the means of two slides were recorded.

Eosinophilic cationic protein (ECP) was measured in the sputum supernatant with a commercial kit (Pharmacia \& Upjohn Diagnostics AB, Uppsala, Sweden) which has a lower limit of detection of $8 \mathrm{pg} / \mathrm{ml}$. Eotaxin levels were measured in induced sputum of asthmatic patients in the low dose study. Part of the sputum sample was dissolved in cold TFA buffer and then stored at $-20^{\circ} \mathrm{C}$. Eotaxin was measured by ELISA using matched paired antibodies (R\&D systems).

\section{Analysis of data}

In the dose finding study we performed comparisons of time points with baseline values. In the placebo controlled studies values after eotaxin were compared with those after placebo. The maximum response over 72 hours was used as a summary measure of the post-inhalation values, and statistical comparisons were performed using these values. Individual time point values were used only to show the time trend of changes. The mean difference (effect size) with $95 \%$ confidence intervals (CI) was computed for sputum cell counts. A paired $t$ test was used for comparisons except for sputum cell counts, sputum ECP levels, and blood eosinophil counts where Wilcoxon signed rank test was used. Statistical significance was defined by a $\mathrm{p}$ value of $<0.05$.

\section{RESULTS}

Dose finding study

There was no obvious trend for a dose-dependent effect of eotaxin. However, by pooling the data in the six asthmatic subjects, we observed a trend toward an increase in sputum eosinophil count at 5 hours $(3.50(0.45) \% v 1.08(0.25) \%$ at baseline, $\mathrm{p}=0.06$ ) which was less obvious at 24 and 72 hours (3.53 $(0.95) \%$ and $4.39(1.86) \%$, respectively) after eotaxin inhlation. There was no change in blood eosinophil count, exhaled $\mathrm{NO}, \mathrm{FEV}_{1}$ or methacholine $\mathrm{PC}_{20}$. We observed no clinical worsening in asthma after eotaxin administration.

\section{Low dose study $(20 \mu \mathrm{g}$ eotaxin)}

Baseline measurements were similar in the two study periods. Neither eotaxin nor placebo inhalation had an effect on $\mathrm{FEV}_{1}$, methacholine $\mathrm{PC}_{20}$, or exhaled NO. Furthermore, there was no difference in blood eosinophil counts between eotaxin and placebo, and no difference in the sputum eosinophil count after eotaxin compared with placebo in asthmatic or normal subjects (table 1). Both eotaxin and placebo induced a similar increase in sputum neutrophil count at 24 hours in asthmatic and normal volunteers (fig 1). There was no difference in ECP levels in sputum samples from asthmatic patients after eotaxin inhalation compared with baseline. To determine whether eotaxin was present in the lungs following inhalation, eotaxin was measured in sputum samples from five asthmatic volunteers after inhalation. Detectable levels of eotaxin were found in three subjects 5 hours after nebulisation with return to baseline values at 24 hours (fig 2).

\section{High dose study (40 $\mu$ g eotaxin)}

Baseline measurements did not differ between placebo and eotaxin inhalation for all the variables studied. Valid sputum specimens for cell counts were obtained at all time points for seven patients. Comparisons were performed for all subjects (intention-to-treat analysis) except for sputum cells. Comparisons were also performed for the seven subjects with complete valid sputum specimens and the results were similar (not shown). We observed no change in $\mathrm{FEV}_{1}$, methacholine $\mathrm{PC}_{20}$, exhaled $\mathrm{NO}$, or circulating eosinophils during the 72 hour observation period after eotaxin inhalation. There was no difference in any of these variables between placebo and eotaxin.

Sputum eosinophil counts did not differ after eotaxin inhalation compared with placebo (figs 3A and 4; 95\% CI for the mean difference crosses the line of no change for the maximum response over 72 hour time course). ECP concentrations in sputum supernatants did not change after either

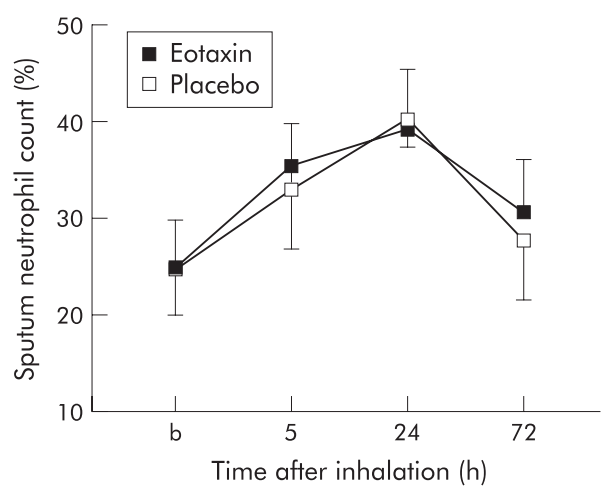

Figure 1 Mean (SE) sputum neutrophil counts in patients with asthma after inhalation of either eotaxin $(20 \mu \mathrm{g})$ or placebo. $b=$ measurement before inhalation (baseline). 


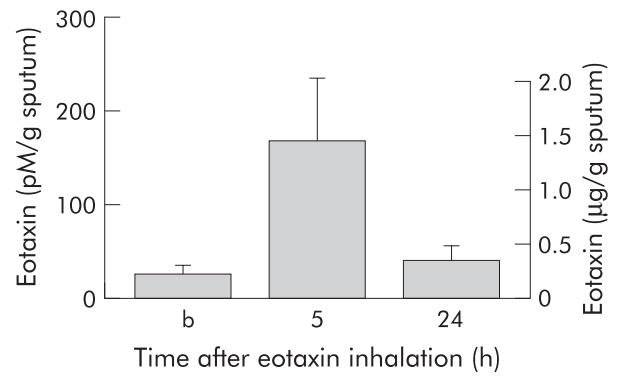

Figure 2 Mean (SE) eotaxin concentration in sputum $(\mathrm{pM} / \mathrm{g}$ and $\mu \mathrm{g} / \mathrm{g}$ ) after eotaxin inhalation in three volunteers in which there were detectable levels. Eotaxin levels were increased at 5 hours and had returned to baseline levels at 24 hours. $b=$ baseline.

eotaxin or placebo inhalation. Sputum neutrophil counts were higher after eotaxin inhalation than after placebo (fig 4, maximum sputum neutrophil count). The time trend of sputum neutrophil count (fig 3B) shows a maximum 24 hours after eotaxin inhalation.

\section{DISCUSSION}

In this first study of inhaled eotaxin in subjects with asthma we did not observe any change in sputum eosinophil count and sputum ECP concentration after inhalation of 20 and $40 \mu \mathrm{g}$ human recombinant eotaxin compared with placebo. Inhalation of eotaxin also had no effect on exhaled NO, blood eosinophil count, lung function (as expressed by $\mathrm{FEV}_{1}$ ), or bronchial hyperresponsiveness. However, we found an unexpected increase in the sputum neutrophil count after inhalation of $40 \mu \mathrm{g}$ eotaxin, with a maximum at 24 hours after inhalation.

The absence of an eosinophil response after eotaxin administration contradicts the findings in previous studies with other species or organs. Administration of eotaxin in the skin is followed by eosinophil influx in guinea pig, ${ }^{15}$ which is increased by intravenous administration of interleukin (IL)-5. ${ }^{13}$ Cutaneous injection of $10 \mu \mathrm{g}$ eotaxin in human volunteers was followed by a significant eosinophil influx beginning at 1 hour and persisting for 24 hours; this was associated with an influx of basophils, macrophages, and, unexpectedly, of neutrophils. ${ }^{14}$ Eosinophil influx was evident with $1 \mu \mathrm{g}$ eotaxin, but neutrophil influx occurred with eotaxin concentrations of $0.01 \mu \mathrm{g} .{ }^{14}$ Administration of eotaxin to the respiratory mucosa has produced variable results. Intranasal administration to mice induced significant eosinophil influx in nasal mucosa only in IL-5 transgenic mice and not in the wild type, ${ }^{15}$ while intranasal administration of $8 \mu \mathrm{g}(4 \mu \mathrm{g} /$ nare $)$ in human atopic volunteers was followed by an eosinophil influx in the nasal lavage fluid. ${ }^{16}$ Eotaxin administration to the lower airways of naïve guinea pigs either by aerosol (24 pmol $\sim 0.2 \mu \mathrm{g}$ in $10 \mathrm{ml}$ in two animals $)^{5}$ or by intratracheal instillation ${ }^{17}$ was followed by an influx of eosinophils into
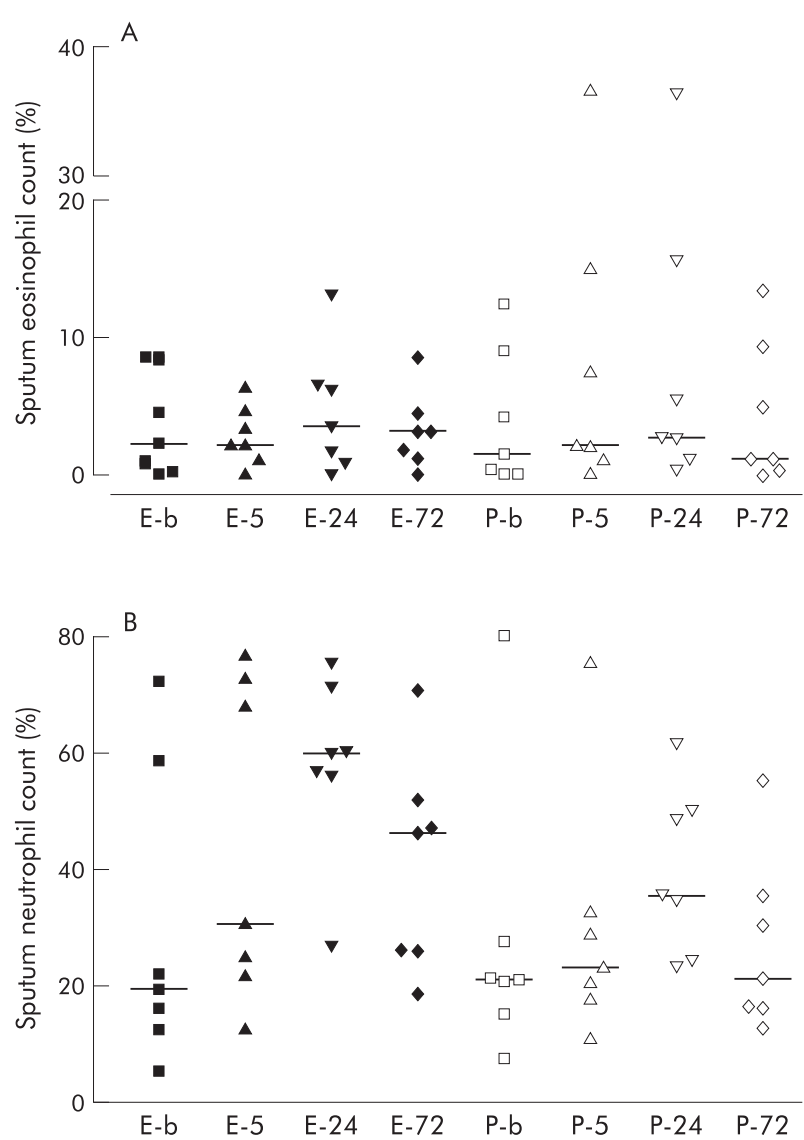

Figure 3 Sputum cell counts for (A) eosinophils and (B) neutrophils. Horizontal bars represent medians. No time trend was seen in eosinophil counts, but there was an increase in sputum neutrophils after eotaxin inhalation which reached a maximum at 24 hours. E-b or $\mathrm{P}-\mathrm{b}=$ baseline measurement after eotaxin or placebo; $\mathrm{E}-5, \mathrm{E}-24, \mathrm{E}-$ $72=$ time in hours after eotaxin inhalation; P-5, P-24, P-72 = time in hours after placebo.

the BAL fluid. On the other hand, intratracheal instillation of up to $5 \mu \mathrm{g}$ eotaxin induced an eosinophil influx in BAL fluid only in IL-5 transgenic mice and not in the wild type. ${ }^{18}$ In another experiment intratracheal instillation of eotaxin $(0.5 \mu \mathrm{g})$ in naïve mice was not followed by any eosinophil influx, even when preceded by intravenous administration of IL-5. ${ }^{19}$

There may be several reasons for our failure to demonstrate the chemotactic effect of eotaxin for eosinophils. Firstly, the dose delivered to the airways may not have been sufficient. This is possible because $10 \mu \mathrm{g}$ was considered the optimal dose for cutaneous injection in humans and $8 \mu \mathrm{g}$ for intranasal administration. In both situations the amount of eotaxin delivered would have been the amount reaching the active site. On the other hand, we found an unexpected but

Table 1 Mean (SE) sputum eosinophil counts (\%) in low dose eotaxin study

\begin{tabular}{llllll}
\hline & Asthma & & & Normal & \\
\cline { 2 - 3 } \cline { 5 - 6 } Time point & Eotaxin & Placebo & & Eotaxin & Placebo \\
\hline Baseline & $0.50(0.29)$ & $0.50(0.29)$ & & $0.53(0.29)$ & $0.53(0.31)$ \\
5 hours & $1.07(0.30)$ & $2.13(1.10)$ & & $0.90(0.78)$ & $0.17(0.13)$ \\
24 hours & $0.47(0.15)$ & $1.42(0.86)$ & & $0.36(0.19)$ & $0.23(0.23)$ \\
72 hours & $0.93(0.23)$ & $0.43(0.11)$ & & $0.63(0.40)$ & $0.40(0.16)$ \\
\hline
\end{tabular}

Comparisons were made using the Wilcoxon signed rank test. 


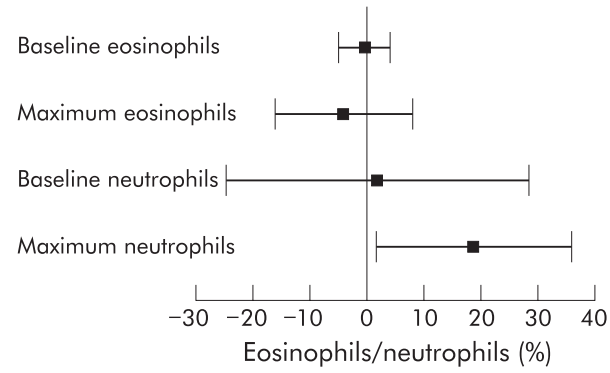

Figure 4 Mean differences with 95\% confidence intervals (Cl) between eotaxin and placebo inhalation in sputum eosinophil and neutrophil counts at baseline and for the maximum response over 72 hours. There was no difference in baseline values and maximum eosinophil count, but a significant increase in neutrophil count was seen after eotaxin inhalation compared with placebo.

clear effect on sputum neutrophil count, which suggests that a significant quantity of eotaxin was delivered to the lower airways. Also, in the low dose study the eotaxin concentration in induced sputum increased 5 hours after eotaxin inhalation to a level of nearly $1.5 \mu \mathrm{g} / \mathrm{g}$ sputum, signalling the presence of a significant amount at the level of the lower airways. It is possible, however, that at higher doses an effect on eosinophils in addition to the effect on neutrophils might have been seen, as in the skin study by Menzies-Gow et al. ${ }^{14} \mathrm{~A}$ second explanation could be that eotaxin is present in excess in the lower airways and the quantity administered in the study did not make any difference. This again is contradicted by the clearcut effect on the neutrophil count.

It is also possible that the study had insufficient power to show an increase in sputum eosinophil count after eotaxin inhalation. The $40 \mu \mathrm{g}$ study actually showed higher sputum eosinophil counts after placebo than after eotaxin. In order to compute the power of our study we used a published value of standard deviation of the difference between duplicate measurements of induced sputum eosinophils of $2.15 \%$ obtained from 84 untreated asthmatics 1 week apart. ${ }^{20}$ Using this value we calculated that our study of seven patients would have been able to show a difference in the sputum eosinophil count of at least $2.3 \%$ with a power of $80 \%$ at a confidence level of $95 \%$. If eotaxin is an effective eosinophil chemoattractant when administered in vivo, a 5\% increase in the eosinophil count might be expected as is seen, for example, after experimental allergen challenge.

It is also possible that other factors (such as IL-5) may be important for eosinophil influx. This would be in concordance with mice studies which have shown an absence of effect in wild type and a clearcut positive effect on eosinophils in IL-5 transgenic mice. ${ }^{18}$ Intravenous IL-5 in human asthmatic volunteers is followed by increased circulating eosinophil progenitors and increased expression of eosinophil CCR3. ${ }^{21}$ These changes could be necessary for eosinophil recruitment by eotaxin in human lower airways. In this case, intravenous administration of IL-5 before eotaxin inhalation may be more successful in attracting eosinophils to the lower airways, and patients with more severe asthma may respond to a greater extent.

We found an unexpected increase in sputum neutrophils after inhalation of high dose eotaxin. This effect was also seen following cutaneous injection. ${ }^{14}$ It is unlikely to be caused by any potential endotoxin contamination as the levels were very low ( $<1.0 \mathrm{EU} / 1 \mu \mathrm{g}$ eotaxin). CCR3 has been shown to be expressed on neutrophils after stimulation with interferon $\gamma \cdot{ }^{22}$ Menzies-Gow et al showed that low levels of CCR3 are present on fresh neutrophils and disappear after purification; ${ }^{14}$ however, they could not find any evidence that this receptor is functional. They concluded that neutrophil influx is secondary to mast cell degranulation with release of neutrophil specific chemotactic factors such as IL-8.

\section{Authors' affiliations \\ D Bumbacea, J Scheerens, B S Mann, R G Stirling, K F Chung, \\ Department of Thoracic Medicine, National Heart and Lung Institute, Imperial College, London SW3 6LY, UK \\ D Bumbacea, Clinica de Pneumologie "Marius Nasta", UMF Carol Davila, Bucharest, Romania}

D Bumbacea was supported by an ERS research fellowship. This study was supported by GlaxoSmithKline Pharmaceutical Company (UK).

\section{REFERENCES}

1 Jose PJ, Griffiths-Johnson DA, Collins PD, et al. Eotaxin: a potent eosinophil chemoattractant cytokine detected in a guinea pig model of allergic airways inflammation. J Exp Med 1994;179:881-7.

2 Ponath PD, Qin S, Post TW, et al. Molecular cloning and characterization of a human eotaxin receptor expressed selectively on eosinophils. J Exp Med 1996; 183:2437-48.

3 Daugherty BL, Siciliano SJ, DeMartino JA, et al. Cloning, expression, and characterization of the human eosinophil eotaxin receptor. J Exp Med 1996; 183:2349-54.

4 Conroy DM, Williams TJ. Eotaxin and the attraction of eosinophils to the asthmatic lung. Respir Res 2001;2:150-6.

5 Griffiths-Johnson DA, Collins PD, Rossi AG, et al. The chemokine, eotaxin, activates guinea-pig eosinophils in vitro and causes their accumulation into the lung in vivo. Biochem Biophys Res Commun 1993;197:1167-72.

6 Ying S, Meng Q, Zeibecoglou K, et al. Eosinophil chemotactic chemokines (eotaxin, eotaxin-2, RANTES, monocyte chemoattractant protein-3 (MCP-3), and MCP-4), and C-C chemokine receptor 3 expression in bronchial biopsies from atopic and nonatopic (intrinsic) asthmatics. J Immunol 1999; 163:6321-9.

7 Lamkhioued B, Renzi PM, Abi-Younes S, et al. Increased expression of eotaxin in bronchoalveolar lavage and airways of asthmatics contributes to the chemotaxis of eosinophils to the site of inflammation. J Immunol 1997; 159:4593-601.

8 Zeibecoglou K, Ying S, Meng Q, et al. Expression of eotaxin in induced sputum of atopic and nonatopic asthmatics. Allergy 2000;55:1042-8.

9 Mattoli S, Stacey MA, Sun G, et al. Eotaxin expression and eosinophilic inflammation in asthma. Biochem Biophys Res Commun 1997;236:299-301.

10 Global Strategy for Asthma Management and Prevention. www.ginasthma.com (accessed 28 January 2003).

11 Stirling RG, Kharitonov SA, Campbell D, et al. Increase in exhaled nitric oxide levels in patients with difficult asthma and correlation with symptoms and disease severity despite treatment with oral and inhaled corticosteroids. Asthma and Allergy Group. Thorax 1998;53:1030-4.

12 Keatings VM, Evans DJ, O'Connor BJ, et al. Cellular profiles in asthmatic airways: a comparison of induced sputum, bronchial washings, and bronchoalveolar lavage fluid. Thorax 1997;52:372-4.

13 Collins PD, Marleau S, Griffiths-Johnson DA, et al. Cooperation between interleukin-5 and the chemokine eotaxin to induce eosinophil accumulation in vivo. J Exp Med 1995; 182:1 169-74.

14 Menzies-Gow A, Ying S, Sabroe I, et al. Eotaxin (CCL11) and eotaxin-2 (CCL24) induce recruitment of eosinophils, basophils, neutrophils, and macrophages as well as features of early-and late-phase allergic reactions following cutaneous injection in human atopic and nonatopic volunteers. $J$ Immunol 2002;169:2712-8.

15 van de Rijn M, Mehlhop PD, Judkins A, et al. A murine model of allergic rhinitis: studies on the role of $\lg E$ in pathogenesis and analysis of the eosinophil influx elicited by allergen and eotaxin. J Allergy Clin Immunol 1998;102:65-74.

16 Hanazawa T, Antuni JD, Kharitonov SA, et al. Intranasal administration of eotaxin increases nasal eosinophils and nitric oxide in patients with allergic rhinitis. J Allergy Clin Immunol 2000; 105:58-64.

17 Fukuyama S, Inoue H, Aizawa H, et al. Effect of eotaxin and plateletactivating factor on airway inflammation and hyperresponsiveness in guinea pigs in vivo. Am J Respir Crit Care Med 2000;161:1844-9.

18 Hisada T, Hellewell PG, Teixeira MM, et al. Alpha-4 integrin-dependent eotaxin induction of bronchial hyperresponsiveness and eosinophil migration in interleukin-5 transgenic mice. Am J Respir Cell Mol Biol 1999;20:992-1000.

19 Scheerens J. Eotaxin, airway inflammation and hyperresponsiveness. PhD thesis: Faculty of Pharmacy, Utrecht University, 2001:84-121.

20 Diukanonic R, Sterk PJ, Fahy JV, et al. Standardised methodology of sputum imduction and processing. Eur Respir J 2002;20(suppl 37): 1s-52s.

21 Stirling RG, van Rensen EL, Barnes PJ, et al. Interleukin-5 induces CD34(+) eosinophil progenitor mobilization and eosinophil CCR3 expression in asthma. Am J Respir Crit Care Med 2001;164:1403-9.

22 Bonecchi R, Polentarutti N, Luini W, et al. Up-regulation of CCR1 and CCR3 and induction of chemotaxis to CC chemokines by IFN-gamma in human neutrophils. J Immunol 1999;162:474-9. 